\title{
Output-based approach in media and information literacy toward 21st century skills development in the Philippines
}

\author{
Santos, Rafael $\bowtie$ \\ University of Asia and the Pacific, Philippines (Rafael.santos@uap.asia)
}

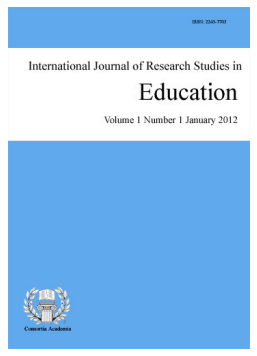

Accepted: 18 September 2020

ISSN: $2243-7703$ Online ISSN: 2243-7711

OPEN ACCESS

\section{Abstract}

The educational landscape, notably the whole-person movement, continues to evolve, with experts and policymakers from various fronts espousing the integration of information and communication technology in pedagogy, the development of life and work skills, and the nurture of the mind and spirit via project-based instruction. A prior examination of the Media and Information Literacy (MIL) for senior high school in the Philippines, however, showed a tendency to teach knowledge transfer and a lack of emphasis on interpersonal and intrapersonal skills development. This research attempted to measure the manifestations of the development of cognitive, interpersonal, and intrapersonal potentials of respondents using a reinvented and project-based 21CC paradigm in teaching MIL, as well as determine any correlation between respondents' demonstration of these potentials in the implementation of the output-based curriculum with their class performance. A 42-item Likert Scale online self-assessment questionnaire was administered to 138 out of the 150 Grade 11 students from five sections between May 19 and 22, 2019, with items pertaining to assessment, group presentations, publication, visual design, audio production, interview, media fasting, and responsible media use. Analysis of quantitative data was done using inferential statistics. Results showed furtherance of cognitive skills development and strong acquisition in the metacognitive skillsets. Furthermore, the Pearson $r$ test revealed strongly significant correlations for cognitive $(r(100)=.307, p<.002)$, interpersonal $(r(100)=.288, p<.003)$, and intrapersonal competencies $(r(100)=.313, p<.001)$, indicating that the newly designed MIL curriculum can enhance cognitive, interpersonal, and intrapersonal skills.

Keywords: cognitive; interpersonal; intrapersonal; 21CC; CII 


\section{Output-based approach in media and information literacy toward 21st century skills development in the Philippines}

\section{Introduction}

The Philippine Department of Education began implementing an expanded basic education curriculum, also known as the K-12 program, in 2016. The new educational policy envisions among others the following:

[E]very graduate... [must be imbued with] creative and critical thinking, and the capacity and willingness to transform others and oneself. ("Republic Act No. 10533," para. 4)

The same law mandates the development of "essential competencies, skills and values for both life-long learning and employment" (para. 5). As part of the modified educational agenda, Media and Information Literacy was introduced in senior high school (SHS) to teach effective use of technology and communication channels. The ultimate goal is to make graduates employable; however, a great majority of SHS finishers cannot secure jobs. While lack of employment opportunities is being blamed (Hernando-Malipot, 2018), quality of the education is also considered a major cause. For instance, a study by the Philippine Institute for Development Studies finds incompatibility between industry needs and acquired graduate attributes. The study stressed that companies prefer SHS "graduates armed with the skills the job market needs" (Pascual, 2019, para. 5). The problem is similar among college graduates. The World Bank reports that Filipino college graduates experience deficit on non-cognitive, social, and behavioral skills, which a majority of employers deem as the most important competencies that they are looking for in applicants (Acosta, Igarashi, Olfindo, \& Rutkowski, 2017). The bank refers to these as "soft skills" or "socioemotional skills" (xiii).

The MIL instruction is meant to achieve a "basic understanding of media and information as channels of communication and tools" and develop creativity, critical thinking, responsible media use, and competent production (Pitagan, Andres, Plaza, Rotor, \& Villanueva, 2016, p. 5). Responsible use of media tools falls under the intrapersonal domain while the rest of the competencies belong to the cognitive sphere. In the government-produced curriculum, competencies are measured via comprehension, repetition, and articulation of content through sharing and discussing, as well as writing. The major tasks are a poster, an infographic, a podcast, a video, and a survey. More important, the course neither intends to teach the use media and information tools nor implements an outcome-based approach; rather, it aims to measure comprehension of 17 topics. A design analysis of MIL curriculum indicates that it fell below the tenets of a 21CC formula, (Santos, 2020). Since no actual hands-on training in undertaking MIL tasks was evident, it appeared that the projects were determined arbitrarily, further showing a lack of intentionality in improving aptitudes. The study stated:

Clearly, the objective of the course is acquisition of subject matter content, and not life and career competencies as envisioned by the government. (Santos, 2020, p. 7)

Thus, a reformulation of the existing MIL curriculum, which is being used nationwide, was recommended in an unpublished design analysis of the course in 2019. Based on the recommendation, the researcher ventured into a semester-long research in 2019, implementing the revised features of the output-based course. The overall goal was to measure the three categories of $21^{\text {st }}$ century skills, particularly cognitive, interpersonal, and intrapersonal (CII) competencies. Specifically, the study attempted to determine the extent by which the three domains were developed or enhanced as students performed the required projects with the use of the project-based CII paradigm.

\subsection{Output-based curriculum in media and information literacy}

Eleven outputs were recommended in the proposed curriculum, and these are assessment via the learning

14 Consortia Academia Publishing (A partner of Network of Professional Researchers and Educators) 
management system (LMS) Canvas, group presentations, book publication, visual media design, audio production, interview of a history professor with a synthesis paper, photography and photo exhibit, text analysis, media fasting with a reflection paper, responsible media and gadgets use, and introspection.

The LMS-based assessment includes regular seat work, quizzes, and two major tests that require the use of gadgets such as laptops, smartphones, and Canvas. The target competencies are cognitive and intrapersonal domains. Group presentations involved two tasks, one at the beginning of the term and the other toward the end. Both must be delivered via ubiquitous media such as Microsoft Power point program, videos, and graphics. The first involves data-gathering of students' media use and the second is about an assigned topic that must be discussed by the student. Cognitive, interpersonal, and intrapersonal are to be developed.

With ethical communication as its goal, the positivity-themed book publication is the major project for the class. Tasks are writing, graphics design and lay-outing, sourcing of funds, copyright registration, and negotiation with potential printers. In this task, cognitive, interpersonal, and intrapersonal spheres are tested. The visual design is to be undertaken by applying the elements of visual techniques. Choices are a poster, an invitation, and a brochure which must be produced using Photoshop, Canva, and other software. Only cognitive and intrapersonal skills are checked in this task. Audio production involves three stages: pre-production, actual production, and post-production. After conceptualization, recording of vocals is done during the production phase. Editing of voice tracks and application of audio effects, sound effects, and music using recording and editing apps and software follow. This project intends to develop cognitive, interpersonal, and intrapersonal skills.

The interview, an individual task, involves asking pertinent questions from history teachers, media professionals, and other experts informed about Philippine media and politics. In particular, the students are to ask regarding media's role in preserving democracy. Results are to be synthesized, integrating key concepts and lessons on media's functions. Three competencies are tested in this output. The photography project consists of two phases - taking of pictures and a one-day exhibit. Rules in photography are applied in capturing images that reflect social, economic, and political issues. For the class exhibit, photographs must be categorized according to genres and captioned accordingly. This individual task requires only the testing of cognitive and intrapersonal competencies.

The text analysis requires reading any of the recommended texts to determine their validity and reliability with a two-page reflection paper about the material and insights from lecture. This individual output also requires only cognitive and intrapersonal skills. Media fasting and reflection paper requires a drastic reduction of media use during a sacred period called Holy Week and entails a reading on responsible media use and writing of a reflection paper. Students must report about the extent of social media control, emphasizing introspective thoughts and realizations, and then connecting the experience with both the reading and lessons covered. An individual project, this task is meant to improve cognitive and intrapersonal skills being an individual project. Responsible media and gadgets use consists of two areas: regulated use in class and responsible use during non-class hours. It is a test of discipline, self-control, and responsibility. This individual project is intended to develop intrapersonal skills. Finally, introspection involves reflections on the lessons, readings, and experiences - all designed to develop this intrapersonal habit while improving writing skills (cognitive).

\subsection{The bumpy road toward $21^{\text {st }}$ century pedagogy}

The road toward achieving the ideals of the so-called $21^{\text {st }}$ century competencies $(21 \mathrm{CC})$ in pedagogy has not been smooth sailing, often facing a plethora of reactions and criticisms from researchers, policymakers and other experts in the educational field and allied sectors. Campbell (2009), for one, sees a lack of unified approach in 21CC, noting divergent frameworks and agenda in planning and implementation. Some fronts, reports Campbell, focus on knowledge transmission while certain groups emphasize skills development, and still others like the religious schools prioritize instilling of values. London (2006) calls this erratic nature of the educational 
landscape as "partial, disjointed, [and] inauthentic" (p. 8). In short, there never has been a cultivation of the whole person from the mind, the heart, and the skills. Even at the turn of the century, researchers were still noticing a tendency to ignore metacognitive skills formation (Heckman \& Rubinstein, 2001). Merrow (2006) is critical of this propensity to highlight comprehension-cum-recall type of education, and laments how high school educators concentrate on subject matter mastery instead of teaching students much-needed independence and critical thinking. He decries what he calls "content driven" approach that train students "to get the right answer" (p. 15). He writes:

\section{It's not enough to stuff students' head with information and ask them to regurgitate it. Too many students leave high school without either a solid grasp of the fundamentals or the habits of mind that make them ready (let alone eager) to explore. (p. 15)}

Although thinking and exploratory skills are a notch higher in learning, Merrow fails to capture the whole concept of holistic nurture. Drew (2012) goes farther to underscore the inadequacy of merely honing technical skills. In his view, teaching and content must be made "robust and relevant to the real world" (p. 328). Such an approach is reflective of "the knowledge and skills that...young people need for success in college and careers" while at the same time "positioning to complete successfully in the global economy" (p. 328). The Welsh government, with the Brexit as a backdrop, concurs and recognizes the paramount importance of skills development both inside and outside the classroom environments rather than mere transfer of knowledge and then "testing it" (Fawcett \& Gunson, 2020, p. 5). Hanushek and Woessmann (2008) support such opinions and connect cognitive skills with one's economic well-being, echoing claims in the mid-80's that purported a correlation between earning capacities and knowledge skills (Boissiere, Knight, \& Sabot, 1985).

A growing corpus of research, however, is veering away from such philosophies and point to the equally critical role of non-cognitive abilities toward career and life success. For instance, as of the late 90's, the demands for the intrapersonal competences via interdisciplinary education was already being highlighted in literature because of the significance of "moral and psychological grounding" among employees (Aristigueta, 1997, p. 163). Experts contend that having strong cognitive skills is no guarantee of economic advancement (Murnane, Willett, Duhaldeborde, \& Tyler, 2000). Vidyarthi (2012) and associates, citing a study by Hoch and Fischler done in 2011, call for a curriculum that is holistic, inclusive, and practical. In their view, holistic means integration of "multiple disciplines" and inclusive refers to "social, political, institutional understanding and technical skills in...decision-making", while practical encompasses both scientific and moral sensitivity (Vidyarthi, 2012, p. 626). Lovat, Clement, Dally, and Toomey (2010) believe this nurture of character or spirit, also known as values formation, has strong connections to successful pedagogy and must not only be confined in the province of faith schools. National governments, particularly, the US National Academy of Sciences, agree, promoting aggressively both cognitive and non-cognitive competencies also referred to as t-shaped skills (Neeley \& Steffensen, 2018). T-shaped thinkers, adept in their own fields, perform "cross-disciplinary collaboration" and are capable of handling technical and social rigors as "new employees of the digital age" (Conley, Foley, Gorman, Denham, \& Coleman, 2015, p. 1).

Decades after the call for the building of internal qualities that are associated with life and work advancement, the quest for what Pellegrino and Hilton (2012) referred to as deeper learning continues to gain momentum (Nehring, Charner-Laird, \& Szczesiul, 2017). This is borne out of the need to guarantee employability and instill citizenship among learners, leading to the conception of truly well-rounded 21CC literacy formulae (Tan, Choo, Kang, \& Liem, 2017). The Partnership for 21 st Century Skills, for instance, advocates a model that builds analytical, collaborative, and interpersonal competencies also known as 4C's (Black, 2009; California Department of Education, 2019; NEA, 2019). Additionally, P21, integrates ICT and life and career skills (Logsdon, 2013). The Assessment and Teaching of $21^{\text {st }}$ Century Skills (AT21CS) paradigm seeks to cultivate citizenship, life and career skills, and personal and social responsibility (Saavedra \& Opfer, 2012). Creativity and innovation, ICT skills and collaborative competencies are also championed. The EU Lifelong Competencies for Lifelong Learning, for its part, mixes entrepreneurship, science, technology,

16 Consortia Academia Publishing (A partner of Network of Professional Researchers and Educators) 
Output-based approach in media and information literacy toward 21 st century skills development

engineering, and mathematics with, social, civic, and cultural adeptness (Hozjan, 2009). The ultimate goal is to produce employable and "future-ready" graduates (Tan, Koh, Chan, Costes-Onishi, \& Hung, 2017, p. 5).

In 2012, Payne and Kyllonen introduced the cognitive-interpersonal-intrapersonal triad, three skillsets that they believe should make up the whole person paradigms. No matter how critical, such competencies, however, "remain under-prioriti[z]ed in educational systems worldwide", favoring the "narrow teaching and learning of factual information" (Wright \& Lee, 2014, p. 200). Moreover, despite the abundance of "new knowledge economy" pedagogical formulations, a limited capacity of 21CC implementation as well as a lack of studies on the subject exist (Tan, Choo, Kang, \& Liem, 2017, p. 427). These are a cause for alarm since as Rosenbaum raised in 1991 all three categories of skills are key to long-term career success and strong contributors of intergeneration income persistence, among others (Blanden, Gregg, \& Macmillan, 2007; Farkas, 2003).

\subsection{Research Concepts and Questions}

It was Nehring, Charner-Laird, and Szczesiul (2017) who proposed the taxonomy cognitive, interpersonal, and intrapersonal $(\mathrm{CII})$ in the pursuit for a genuine $21^{\text {st }}$ century education. They posit that these three domains must be the hallmarks of a well-rounded instruction, not just information transfer and/or possession of employment skills. In fact, cognitive competencies are dependent on one's non-cognitive abilities (Billing, 2007). In addition, a 21CC paradigm can be much more effective if the output-based method is adopted. Herman, Dinicola, Armentrout, and Ross (2019), citing "substantial amounts of research" (e.g., Bell, 2010; Pellegrino \& Hamilton, 2012; Saavedra \& Opfer, 2012; \& Trilling \& Fadel, 2012) assert that "project-based learning" is the best route to transmitting $21^{\text {st }}$ century skills (p. 3). Using output-based CII model as inspired by Nehring et al. (2017) and Herman et al. (2019), this study investigated the manifestations of these skills based on the survey and performance of students.

This study attempted to measure the manifestations of cognitive and metacognitive skills via the implementation of a revised MIL curriculum. The specific research questions are:

1. To what extent did the respondents develop cognitive skills in the implementation of the output-based curriculum based on the self-assessment survey?

2. To what extent did the respondents develop intrapersonal abilities in the implementation of the output-based curriculum based on the self-assessment survey?

3. To what extent did the respondents develop intrapersonal skills in the implementation of output-based curriculum based on the self-assessment survey?

4. Does respondents' demonstration of cognitive, interpersonal, and intrapersonal competencies in the implementation of the output-based curriculum correlate with their class performance (grades)?

\subsection{Theoretical Framework}

This study is anchored on the constructivist theory of learning as influenced by Jean Piaget, the father of cognitive theory of learning which served as a foundation for constructivism (Lamon, 2020). According to Piaget's theory of cognitive constructivism, people are responsible for constructing their own individual knowledge and meaning arising from their experiences. McLeod (2019), referring to the work of Elliott and colleagues published in 2000 , refer to this meaning-making as active construction. In short, learning is not innate but experiential in nature. This perspective holds that individuals are never passive in learning, but that they constantly build on previously acquired knowledge as they interact with new realities. This "active engagement with the world" via experiments provides an opportunity for the creation of "a collaborative problem-solving environment where students become active participants in their own learning" (McLeod, 2019, para. 28). This viewpoint highlights the diminished role of teachers as facilitators rather than instructors, and the shift to student-centered approach in pedagogy. In such an environment, the teacher simply guides or acts as a coach in 
order to assist--also known as scaffolding--rather than dictate the direction of learning. The goal is not transmission of information but supporting the knowledge construction (Lefoe, 1998). Here, the student performs a bigger role in charting the direction of the total learning experience as the teacher scaffolds through constant interaction and collaboration or group work. McLeod (2019) illustrates, citing the 2009 work of Copple and Bredekamp, that scaffolding is accomplished through skills modeling, giving of cues or hints, and "adapting material or activity" (para. 32).

To realize this Piagetian principle, proponents of such theory underscore the need for the creation of constructivist learning environments (CLE's). CLE's are characterized by a number of features. Lefoe (1998), citing the 1996 work of Wilson, lists these features as the learning space or place itself and the learner. Also known as setting, space is the venue for learning which entails interactions between and among other learners. Honebein (1996), building on the whole principle of constructivism as it relates to actual classroom setting, enumerates seven pedagogical goals in all constructivist learning settings:

$>$ To provide experience with the knowledge construction process. This means learners determine the content and methods.

$>$ To provide experience in and appreciation for multiple perspectives. Students consider options to solving real-world issues and problems, which add to their learning process.

> To embed learning in realistic contexts. Students deal with "authentic" learning tasks (Honebein, 1996, pp. 11-12).

$>$ To encourage ownership and a voice in the learning process. Learning is designed with the student in mind, and spoon-feeding is avoided.

$>$ To embed learning in social experience. This entails student-teacher collaboration and student-student collaboration.

$>$ To encourage the use of multiple modes of representation. This goal promotes media and technology use in delivery of content and in the execution of student tasks. Specifically, multiplatform strategy using audio, video, and others is given importance.

$>$ To encourage awareness of the knowledge construction process. This entails introspections or metacognition, which reflects analysis of knowledge construction (McLeod, 2019). Honebein (1996) calls this "constructivist learning [as] knowing how we know" (p. 12).

\section{Materials and Methods}

Participants in this study were Grade 11 students enrolled in MIL courses at the University of Asia and the Pacific (UA\&P) in Pasig City. The classes were taught by the researcher himself. The population was selected using non-probability sampling, particularly, purposive or judgmental sampling. Taherdoost (2016), citing the 1996 work of Maxwell, explains that this type of sampling is helpful when particular persons ought to be selected deliberately to ensure the collection of pertinent data, which cannot be obtained from other sources or participants. In this investigation, it was intended to include all UA\&P Grade 11 students, who totaled 150, since their self-assessment as MIL students was necessary to accomplish the research. The participants, who are also known as junior college year 1 students, accomplished the survey between May 19 and 22, 2019 upon the culmination of their media and technology course. Out of 150 students, 138 answered the survey, representing a response rate of $88 \%$, which is considered more than sufficient.

This study is quantitative in nature and employed the survey method to collect data from the target respondents. To assess the effectiveness of the activities in building the CII skills, a self-assessment post-activity survey in English was designed. The Google online survey was a 5-point Likert scale where the subjects were

18 Consortia Academia Publishing (A partner of Network of Professional Researchers and Educators) 
asked to rate how each of the given statement applied to them. The 1-point rating represents the lowest applicability ("Strongly Disagree") and the 5-point rating represents the highest applicability ("Strongly Agree"). There were 42 questions in total. The number of statements per category varies from 1 to 3 , with 1 being the lowest and 3 the highest number. There were 15 questions under the cognitive domain, 10 under interpersonal sphere, and 17 in the intrapersonal field. The last category was assigned more questions since two of the eight projects included in the experiment focused solely on intrapersonal potentials.

The three CII categories were determined based on the concepts of Nehring et al. (2017), who proposed the cognitive, interpersonal, and intrapersonal taxonomy, and Herman et al. (2019), who emphasized the importance of project-based instruction. Under each skillset, three specific competencies were drawn from Georgia Institute of Technology's (n.d.) list. The institution enumerated problem-solving, critical thinking, and creativity as representative of cognitive domain. All three were adopted in the questionnaire. Under interpersonal category, GeorgiaTech provided communications, leadership, and teamwork. All three were also used in the instrument but the first skill was changed to interpersonal communication. The said skill often relates to confidence and facility in interactive situations in addition to clarity in the transfer of information. Finally, five skills were recommended by the American IT school in the intrapersonal domain, and these are adaptability, initiative, discipline, ethics, and persistence. For consistency, only three competencies were utilized in this study namely, persistence, responsibility, and moral judgment, which was in place of ethics. Responsibility, which encompasses adaptability, initiative, and discipline was adopted instead of the three.

To determine the validity of the research approach, a pilot-testing using a printed version of the survey was conducted on May 15, 2019 for a possible improvement of the design, if any. Out of the targeted population, three Grade 11 MIL students-one male and two females-were randomly selected to participate in the pilot test. All three fit the target participant criteria, namely, a student currently enrolled in the technology classes and who must be willing to take part in the initial run. The participants spent between 3 and 5 minutes in answering the pre-test. After the preliminary run of the survey, the students were asked to answer questions to determine the validity and reliability of the instrument. Despite the number of the statements in the instrument, the three participants found the material easy to accomplish, adding that they did not encounter any difficulty in answering any of the questions. All pilot-testers reported that all the statements were clear and that the vocabulary used was understandable. They indicated that the survey could be accomplished without any difficulty by the rest of the target population, proving the validity and reliability of the design. Based on the feedback, the instrument did not undergo any modification and an actual survey commenced four days later.

In order to determine the self-assessment of the respondents' $21 \mathrm{CC}$ competencies, the ratings they assigned for the statements were grouped in accordance with the statement classification scheme, that is, the scores were grouped according to the three CII skills they pertain to: the cognitive, interpersonal and intrapersonal skill. From these, three average scores were obtained per student: the average cognitive score, the average interpersonal score, and the average intrapersonal score. To assess these average scores, an index scoring mechanism was introduced. The index scoring designed was a modified version of the Likert Scale wherein the scores were transformed as continuous values. Such scoring mechanism is advantageous as it can take into account the decimal values that will arise once the Likert Scale scores were averaged. Following data collection, analysis was done using inferential statistics, from which conclusions were extracted.

\section{Findings and Discussion}

The findings of this study are drawn from the implementation of an output-based CII model of 21st century pedagogical framework proposed by the researcher in 2019. They reveal the extent of cognitive, interpersonal, and intrapersonal skills development which were measured through a self-assessment online survey that asked the students to rate their acquisition of the three categories of skills. In cognitive area, the study examined the extent of acquisition of problem-solving, critical thinking, and creativity. The interpersonal domain investigated interpersonal communication, teamwork, and leadership while in the intrapersonal sphere, persistence, 
Santos, R.

responsibility, and moral judgment were tested. Note that although 11 projects were required of the students, only eight were reflected in this study as previously stated. For instance, photography was excluded since graphic design and other related tasks were involved in the visual information design and the book project. Introspection was also set aside since reflection was integrated in both book project and media fasting.

Tables 1-8 show the CII skill categories and the number of statements per skillset. Domains that are not tested do not reflect any statements. In addition, note that the number of statements per skill category varies from 1 to 3 , with 1 being the lowest number and 3 the highest.

\section{Table 1}

Assessment/tests statements by CII skill category

\begin{tabular}{cll}
\hline Categories & & \multicolumn{1}{c}{ Items } \\
\hline & 1. & $\begin{array}{l}\text { I developed my analytical or critical thinking skills in answering the seat work, quizzes, and major } \\
\text { Cogams }\end{array}$ \\
& 2. & I demonstrated my learning in MIL by giving correct answers and essays in the tests \\
& 3. & In difficult sections of the tests, I found solutions so that I could complete all of them \\
\hline Interpersonal & n/a & \\
\hline Intrapersonal & n/a
\end{tabular}

Tables 1 list the assessment statements, totaling three, by CII skill category. In the assessment tasks, only the cognitive domain was measured as recommended in the design analysis (Santos, 2020). The rationale is that seat work, quizzes, and major exams were primarily intended to determine cognitive skills, namely critical thinking, problem solving, and creativity.

Table 2

Group presentations statements by CII skill category

\begin{tabular}{|c|c|}
\hline Categories & Items \\
\hline Cognitive & $\begin{array}{l}\text { 4. I was able to determine which information was needed for our presentations } \\
\text { 5. I helped find solutions to some difficult aspects of our presentations } \\
\text { 6. My group created an excellent and visually appealing presentation that was complete with } \\
\text { PowerPoint slides and some audio-visuals }\end{array}$ \\
\hline Interpersonal & $\begin{array}{l}\text { 7. My speaking skills improved through our class presentations } \\
\text { 8. I learned to coordinate and work with my group for the presentations } \\
\text { 9. It was normal for me to step up when my teammates were hesitant to lead or initiate something } \\
\text { regarding our presentations }\end{array}$ \\
\hline Intrapersonal & $\begin{array}{l}\text { 10. I was patient with my teammates and in completing my assigned tasks } \\
\text { 11. My teammates did not have to remind me to complete my tasks and I made sure I contributed enough } \\
\text { 12. We followed the rules regarding research and plagiarism in completing this project }\end{array}$ \\
\hline
\end{tabular}

All three CII types are measured in group reporting project as shown by Table 2. Each skill domain was assigned three questions. This group activity involved research and writing, design of PowerPoint slides, and oral presentation, thus, the possible development of critical thinking, problem solving, and creativity. To complete the project, group members must collaborate which entails the skills of teamwork, leadership, and interpersonal communication, all of which represent interpersonal skillset. Patience, responsibility, and perseverance, which all belong to the intrapersonal aspect, were also tested since these skills were deemed important in completing the group project.

Table 3

MIL book publication project statements by CII skill category

\begin{tabular}{ll}
\hline Categories & \multicolumn{1}{c}{ Items } \\
\hline \multirow{3}{*}{ Cognitive } & 13. I developed critical thinking skills in writing for and in producing this book \\
& $\begin{array}{l}\text { 14. I helped produce texts, graphics, layout ideas, etc. for the completion of the book } \\
\text { 15. I learned how to solve problems, or I tried to find solutions so that I could help my group complete } \\
\text { the MIL book project }\end{array}$ \\
\hline
\end{tabular}

20 Consortia Academia Publishing (A partner of Network of Professional Researchers and Educators) 
Output-based approach in media and information literacy toward 21 st century skills development

Table 3 ...continued

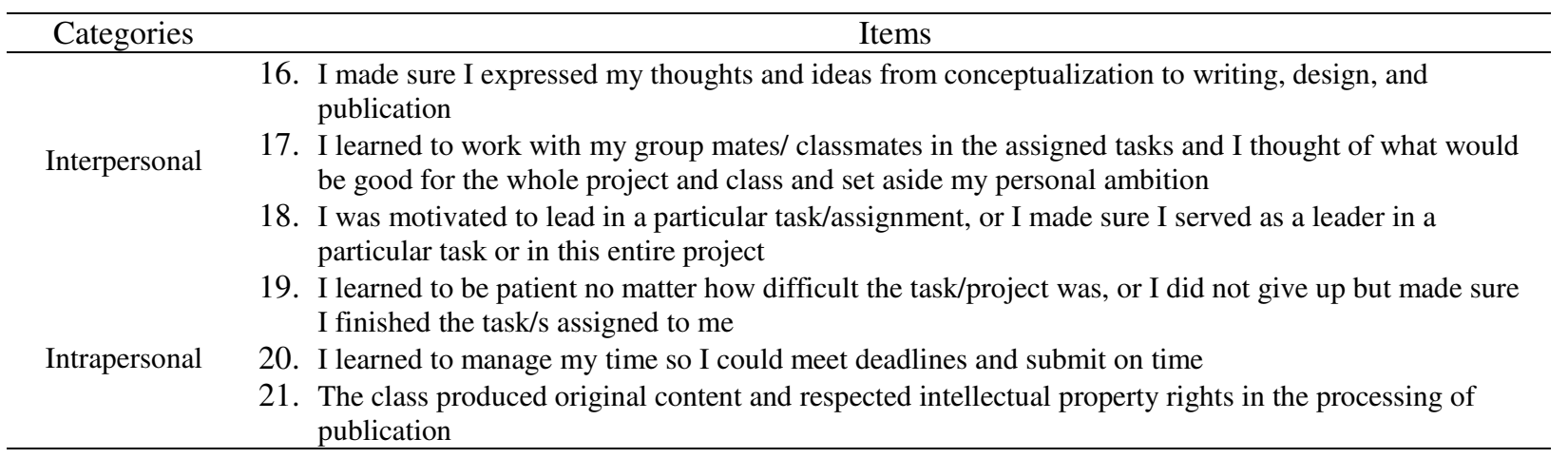

Table 3 shows the extent by which the CII skillsets were measured. Each category was assigned three statements. Being a class project, this task involved delegation of group and individual work among students. Completion of the work entailed collation of previously written material (from introspection notebooks), graphic design, lay-outing, writing and editing, marketing, and administrative and coordination tasks. To finish this major project, the respondents were expected to demonstrate all three major groups of competencies.

\section{Table 4}

Visual information design task statements by CII skill category

\begin{tabular}{cl}
\hline Categories & \multicolumn{1}{c}{ Items } \\
\hline \multirow{2}{*}{ Cognitive } & 22. I developed my creativity regarding visuals, and I designed an excellent poster/invitation/ brochure \\
& 23. I tried to find solutions to my difficulty in designing this visual project \\
\hline Interpersonal & n/a \\
\hline \multirow{2}{*}{ Intrapersonal } & 24. I never gave up until I finished this visual project \\
& 25. I did not only finish the project, but I also did it well and submitted it on time \\
\hline
\end{tabular}

The visual design project, being individually assigned, required the development of two skillsets onlycognitive and intrapersonal. As shown in Table 4, two statements were assigned in each skill category with cognitive measuring creativity and problem solving and intrapersonal measuring perseverance and responsibility.

\section{Table 5}

Audio information project statements by CII skill category

\begin{tabular}{cl}
\hline Categories & \multicolumn{1}{c}{ Items } \\
\hline Cognitive & $\mathrm{n} / \mathrm{a}$ \\
\hline \multirow{3}{*}{ Interpersonal } & 26. My teammates and I held a brainstorming session to decide on how to handle the project, and which \\
& $\begin{array}{l}\text { 27. We produced an excellent audio material } \\
\text { 28. I learned how to cooperate with my teammates }\end{array}$ \\
\hline \multirow{3}{*}{ Intrapersonal } & $\begin{array}{l}\text { 29. I had to take the lead when my team makes needed direction or help } \\
\text { 30. I learned to be persistent - I did not give up until I completed my task for this project } \\
\end{array}$ \\
31. I learned to be responsible in doing this project
\end{tabular}

Three statements were assigned under interpersonal and intrapersonal domains as shown in Table 5, and no cognitive statements were given since it is a group project that required collaboration and a test of character. Therefore, the researcher deemed it necessary to focus only on the two aspects as also recommended in the revitalized MIL curriculum (Santos, 2019; 2020).

Table 6 shows the number of statements used in each skillset in the completion of the interview project: two for cognitive and one each for interpersonal and intrapersonal fields. Under cognitive, problem solving and creativity were measured since the students were expected to produce their own interview questions synthesize interview results, and integrate lessons learned in class. The interpersonal communication was tested in interpersonal domain since respondents were to set up an appointment for an interview and conduct the actual 
Santos, R.

task. Under intrapersonal competency group, moral judgment was determined since students were to submit a paper that was free from plagiarism and written with proper citations and referencing.

Table 6

Interview and synthesis statements by CII skill category

\begin{tabular}{|c|c|}
\hline Categories & Items \\
\hline Cognitive & $\begin{array}{l}\text { 32. I was able to determine which content of the interview was important and needed for the reflection } \\
\text { paper } \\
\text { 33. I was able to submit an excellent interview paper }\end{array}$ \\
\hline Interpersonal & 34. My interpersonal communication skills improved in performing this task \\
\hline Intrapersonal & $\begin{array}{l}\text { 35. I made sure I acknowledged my source/s through proper citation and referencing in writing the } \\
\text { interview paper }\end{array}$ \\
\hline
\end{tabular}

Table 7

Media and gadgets fasting and reflection paper statements by CII skill category

\begin{tabular}{cl}
\hline Categories & \multicolumn{1}{c}{ Items } \\
\hline \multirow{2}{*}{ Cognitive } & $\begin{array}{l}\text { 36. I was able to connect the reading with my media fasting } \\
\text { 37. I was able to write an excellent reflection paper }\end{array}$ \\
\hline Interpersonal & n/a \\
\hline & $\begin{array}{l}\text { 38. I was able to endure with limited media and gadgets use during the fasting period } \\
\text { Intrapersonal }\end{array}$ \\
$\begin{array}{l}\text { 39. I made sure I did the media and gadgets fasting no matter how difficult it was } \\
\text { 40. I made sure I acknowledged source/s through proper citation and referencing in the writing of the } \\
\text { reflection paper }\end{array}$
\end{tabular}

Two major fields were measured in the media and gadgets fasting, which also involved writing of a reflection paper as shown in Table 7. Under cognitive aspect, problem solving and creativity were tested while in intrapersonal domain, perseverance and responsibility were determined. Since this is an individual task, the collaborative interpersonal aspect was not included.

\section{Table 8}

Responsible use of media and gadgets statements by CII skill category

\begin{tabular}{cl}
\hline Categories & Items \\
\hline Cognitive & $\mathrm{n} / \mathrm{a}$ \\
\hline Interpersonal & $\mathrm{n} / \mathrm{a}$ \\
\hline & $\begin{array}{l}\text { 41. I used media and technology tools in classroom only as permitted } \\
\text { Intrapersonal }\end{array}$ \\
& $\begin{array}{l}\text { 42. Outside school, I used new media and technology when necessary. Also, I used media and technology } \\
\text { tools to help others, not malign or bash them }\end{array}$ \\
\hline
\end{tabular}

Table 8 reflects the scope of the responsible use of media and gadgets. In this task, only the intrapersonal aspect was measured since this was purely a test of character, hence, responsibility, which relates to discipline, and moral judgment were determined.

\subsection{Index value per construct}

The following data connect with research questions 1, 2, and 3, which measure the extent of the development of cognitive, interpersonal, and intrapersonal skills using a project-based CII teaching paradigm in the media literacy course. The self-assessment survey was disseminated to all the MIL classes at the end of the second semester. This covers all the five MIL sections: 16YP1, 16YP2, 16YP3, 16YP4, and 16YP5. In total, there are 156 students in these sections. Based on the survey, a total of 138 students responded to the survey that is, $88 \%$ overall response rate, which is considered substantial. Note that the response rate is calculated by obtaining the percentage of those who responded with respect to the population of a given section. The breakdown of the number of respondents and response rate by section is shown in Table 9 below. 
Table 9

Number of respondents and response rate by class section

\begin{tabular}{|c|c|c|c|}
\hline Section & Class population & Number of Respondents & Response rate (in \%) \\
\hline Section 1 & 31 & 29 & $94 \%$ \\
\hline Section 2 & 32 & 27 & $84 \%$ \\
\hline Section 3 & 32 & 28 & $88 \%$ \\
\hline Section 4 & 31 & 30 & $97 \%$ \\
\hline Section 5 & 30 & 24 & $80 \%$ \\
\hline TOTAL & 156 & 138 & $88 \%$ \\
\hline
\end{tabular}

In this study, the respondents engaged in self-assessment via the online survey. The participants' CII abilities were determined. The ratings assigned for the statements were then grouped according to the statement classification scheme set in Tables 1-8. As shown in the following tables, scores were grouped according to the three skillsets they pertain to. Three average scores were obtained per student: the average cognitive score, the average interpersonal score, and the average intrapersonal score. The index scoring was used in the assessment of the average scores. This design represented a modified version of the Likert Scale wherein the scores were transformed as continuous values. This mechanism is advantageous since it can take into account the decimal values that will arise once the Likert Scale scores were averaged. Table 10 below shows the index scoring mechanism, outlining the range of average scores and their corresponding levels in terms of skills acquisition.

Table 10

Index value and interpretation

\begin{tabular}{cc}
\hline Index Value & Interpretation \\
\hline $0.00-0.99$ & Very low \\
$1.00-1.99$ & Low \\
$2.00-2.99$ & Moderate \\
$3.00-3.99$ & High \\
$4.00-5.00$ & Very high \\
\hline
\end{tabular}

The respondents' average scores in Table 10 indicate the corresponding levels of skills acquisition in key areas in completing tasks.

\section{Table 11}

Overall self-assessment indices

\begin{tabular}{cc}
\hline Category of Skills & Average index value \\
\hline Cognitive & 4.21 \\
Interpersonal & 4.32 \\
Intrapersonal & 4.49 \\
\hline
\end{tabular}

Table 11 shows the students' cognitive index is recorded at 4.21, representing a very high or significant acquisition of knowledge-related competencies. The interpersonal domain received 4.32 , also indicating a very high competency index. The table further shows that the intrapersonal area is the most well-developed with 4.49 (very high). Overall, respondents perceived a very high acquisition of the three skills particularly those that deal with character formation or intrapersonal aptitudes. Data suggest that intrapersonal potentials can be highly developed as shown by the high index score. Note that seven of the eight tasks tested the interpersonal skills, a factor that might have influenced the very high rating for intrapersonal index.

Table 12

Index value and interpretation

\begin{tabular}{cc}
\hline Category of skills & Assessment tasks \\
\hline Cognitive & 3.79 \\
Interpersonal & $\mathrm{n} / \mathrm{a}$ \\
Intrapersonal & $\mathrm{n} / \mathrm{a}$ \\
\hline
\end{tabular}


Santos, R.

The Table 12 shows the specific skill that was measured in assessment: cognitive. Other abilities were not tested since this area is purely cognitive in nature. Compared with the other seven activities, assessment got the lowest index (3.79). Nevertheless, the figure is equivalent to high acquisition. As previously stated, only the cognitive category was measured in the assessment activities. The rationale is that assessments focused mainly on developing critical thinking, problem-solving, and creativity. Thus, Table 11 does not reflect any scores under interpersonal and intrapersonal domains.

\section{Table 13}

Index value and interpretation

\begin{tabular}{cc}
\hline Category of skills & Group presentations \\
\hline Cognitive & 4.33 \\
Interpersonal & 4.30 \\
Intrapersonal & 4.57 \\
\hline
\end{tabular}

Group presentations tested all three domains as shown in Table 13. Of the three indices, the intrapersonal aspect got the highest score, which is 4.57, indicating a very high acquisition in the "applied skills" (Silva, 2009, p. 630). The cognitive domain averaged 4.33 , which is also within the very high value while the interpersonal aspect scored an average of 4.30 , indicating a very high development of the skillset. The data show that all three skill domains were highly developed in the completion of MIL projects.

\section{Table 14}

Index value and interpretation

\begin{tabular}{cc}
\hline Category of skills & Book publication \\
\hline Cognitive & 4.21 \\
Interpersonal & 4.29 \\
Intrapersonal & 4.48 \\
\hline
\end{tabular}

Table 14 presents the average index in the development of each skillset. Of the three competencies measured in the publication project, intrapersonal index garnered the highest average with a total of 4.48 points, followed by the interpersonal domain with 4.29 average, and lastly, by the cognitive aspect with 4.21 . All three groups were highly developed as suggested by the data.

\section{Table 15}

Index value and interpretation

\begin{tabular}{cc}
\hline Category of skills & Visual design \\
\hline Cognitive & 4.21 \\
Interpersonal & $\mathrm{n} / \mathrm{a}$ \\
Intrapersonal & 4.49 \\
\hline
\end{tabular}

Of the two competencies that were measured in the visual information project, the intrapersonal index garnered higher with 4.49 , indicative of very high acquisition as shown in Table 15 . The cognitive field received 4.21 , also indicating a very high development of the knowledge skills.

\section{Table 16}

Index value and interpretation

\begin{tabular}{cc}
\hline Category of skills & Audio project \\
\hline Cognitive & 4.33 \\
Interpersonal & 4.45 \\
Intrapersonal & 4.61 \\
\hline
\end{tabular}

The audio project measured all three skill groups. Table 16 reveals that all groups were very highly developed although intrapersonal scored the highest (4.61) and cognitive being the lowest (4.33). 
Table 17

Index value and interpretation

\begin{tabular}{cc}
\hline Category of skills & Interview project \\
\hline Cognitive & 4.18 \\
Interpersonal & 4.21 \\
Intrapersonal & 4.36 \\
\hline
\end{tabular}

In the interview task (Table 17), the three domains were measured, and intrapersonal emerged as having the highest index score with a total of 4.36 average. The interpersonal aspect is ranked second with 4.21 , followed by the cognitive competencies with 4.18. Despite the variation, all three scores are within the very high level, indicating that respondents' CII skills were highly developed.

\section{Table 18}

Index value and interpretation

\begin{tabular}{cc}
\hline Category of skills & Media fasting and paper \\
\hline Cognitive & 4.28 \\
Interpersonal & $\mathrm{n} / \mathrm{a}$ \\
Intrapersonal & 4.32 \\
\hline
\end{tabular}

As an individual activity, media fasting tested only the cognitive and intrapersonal skills as shown in Table 18. Scores are not very far from each other although the intrapersonal field scored higher with an average of 4.32 while the cognitive side got an average of 4.28 .

\section{Table 19}

Index value and interpretation

\begin{tabular}{cc}
\hline Category of skills & Responsible media use \\
\hline Cognitive & $\mathrm{n} / \mathrm{a}$ \\
Interpersonal & $\mathrm{n} / \mathrm{a}$ \\
Intrapersonal & 4.54 \\
\hline
\end{tabular}

Responsible media use was purely a test on intrapersonal competencies since it focused on honesty, discipline, and responsibility as shown in Table 19. Responses in this domain had an average index of 4.54, demonstrating a very high acquisition of internal traits.

\section{Table 20}

Index value and interpretation

\begin{tabular}{ccc}
\hline Category of skills & Start & End \\
\hline Cognitive & 4.33 & 4.33 \\
Interpersonal & 4.30 & 4.29 \\
Intrapersonal & 4.57 & 4.58 \\
\hline Overall index & 4.40 & 4.36 \\
\hline
\end{tabular}

Table 20 shows that at both the start and end of the semester, a very high cognitive index (4.33) was recorded. Interpersonal and intrapersonal indices slightly declined from 4.30 to 4.29 and from 4.57 to 4.48 , respectively. The findings suggest that the overall levels in both fields declined slightly; however, the drop is negligible and insignificant. Students' competencies remain relatively static at the very high level regardless of the period. Overall index was recorded at 4.40 at the start and declined to 4.36. To iterate, the decline has no significant effect on the level of acquisition, which remained consistent at a very high level.

\subsection{Correlation survey data and students' class scores}

The following findings correspond to research question number 4, which sought to establish any correlation between the survey responses and the performance scores of the respondents. For the Pearson $r$ test, 36 responses 
were excluded as they did not contain any email addresses or names that would enable the researcher to link the responses to their individual class performance. The new sample size for the Pearson $r$ test is 102. The results of the Pearson $r$ test reveal that there is a significant correlation between the respondents' cognitive scores and their class performance, $r(100)=.307, p<.002$. Correlation is significant at the .01 level. This indicates that the new MIL output-based curriculum seems to be effective in terms of developing cognitive competencies, namely, creativity, problem solving, and critical thinking.

Following an analysis, the results of the Pearson $r$ test reveal that there is a significant correlation between the respondents' interpersonal scores and their class performance, $r(100)=.288, p<.003$. This suggests that the new MIL output-based curriculum seems to be effective in terms of developing interpersonal skills, namely, interpersonal communication, teamwork, and leadership. Finally, the results of the Pearson $r$ test reveal that there is a significant correlation between the respondents' intrapersonal scores and their class performance, $r(100)$ $=.313, p<.001$. This implies that the new MIL output-based curriculum seems to be effective in terms of developing intrapersonal competencies, namely, persistence, responsibility, and moral judgment.

In summary, students developed all three essential 21CC skillsets namely, cognitive, interpersonal, and intrapersonal potentials as indicated by the data. Of the three domains, the intrapersonal sphere was the most highly developed, reflecting $21^{\text {st }}$ century core competencies that "constitute a multifunctional package of knowledge, skills and values that all individuals require for their personal fulfilment and development, and for their social inclusion and employment" (Hozjan, 2009, p. 201). As in all findings, it is clear that the eight projects were successful in maximizing the use of all the three whole person categories of competencies. Results of the study may have been influenced by two factors. As students, respondents expected themselves to complete the assigned projects satisfactorily in order to at least pass the course. Therefore, although the revised MIL curriculum appeared to have affected the development of $21^{\text {st }}$ century skills, such development may not be entirely attributable to the implementation of the new curriculum. The researcher realizes that although the output-based CII approach was instrumental in developing 21CC competencies among the respondents, one semester may be insufficient to be fully representative of actual skills development.

As per the findings, the researcher proposes the phrase enhancement of skills as more fitting rather than development of skills. The former is indicative of some progress, which this study noted, while the latter assumes sufficient and even full development. Nevertheless, it is proper to reiterate the assertion that data results are indicative of strong possibility of furthering the acquisition of the three skill sets in question.

\section{Conclusion and Recommendation}

Results of this study are ground-breaking, and they offer wide-ranging implications for pedagogical practice as well as for policymakers, educators, and learners. First, they bring to the fore the weakness of the current curriculum guide for Media and Information Literacy, notably its lack of intentionality in building 21st century skills that are labeled as CII competencies in this pioneering work. The findings present a challenge as well as a call for policymakers to consider crafting a constructivist, output-based curriculum that integrates the development of cognitive, interpersonal, and intrapersonal skills in basic education consistent with the goals of the K-12 law of 2016. Doing so will make Philippine brand of senior high school program aligned or compliant with the 21CC ideals that prepare learners toward career, life, and world challenges. Secondly, this research suggests that the same approach can be adopted from the basic education to the tertiary level to bridge the wide gap between educational training and industry needs. Schools can and will be able to produce graduates who possess adequate skills only if instruction is adjusted according to the results of this study.

Beyond employability, which revolves around cognitive and interpersonal competencies, intrapersonal skills were highlighted in this study. This is one of the contributions of this research in literature-that intrapersonal potentials, which are often neglected in the classroom, should now become a priority in educating students. More importantly, science and technology courses as well as those from the liberal arts tradition can be humanized 
Output-based approach in media and information literacy toward 21st century skills development

with the intentional integration of non-cognitive skills teaching. Singapore has for a long time recognized that developing internal attributes are as important if not more important in producing well-rounded graduates who are ready to survive in a globalized world and other debacles which are surmountable only to those who are properly nurtured from kindergarten to college. The same can also be achieved in the Philippines.

\section{References}

Acosta, P., Igarashi, T., Olfindo, R., \& Rutkowski, J. (2017). Developing socioemotional skills for the Philippines' labor market: Directions in development. World Bank. https://doi.org/10.1596/978-1-4648-1191-3

Aristigueta, M. (1997). Strategy and theory for intrapersonal development in public administration education. Journal of Public Administration Education, 3(2), 163-176. https://doi.org/10.1080/10877789.1997.12023426

Billing, D. (2007). Teaching for transfer of core/key skills in higher education: Cognitive skills. Higher Education, 53(4), 483-516. https://doi.org/10.1007/s10734-005-5628-5

Black, R. (2009). English-language learners, fan communities, and 21st-century skills. Journal of Adolescent \& Adult Literacy, 52(8), 688-697. https://doi.org/10.1598/JAAL.52.8.4

Blanden, J., Gregg, P., \& Macmillan, L. (2007). Accounting for intergenerational income persistence: Noncognitive skills, ability, and education. The Economic Journal, 117(519), C43-C60. https://doi.org/10.1111/j.1468-0297.2007.02034.x

Boissiere, M., Knight, J., \& Sabot, R. (1985). Earnings, schooling, ability, and cognitive skills. The American Economic Review, 75(5), 1016-1030.

California Department of Education. (2019). Partnership for 21 st century skills. https://www.cde.ca.gov/eo/in/cr/p21cskls.asp

Campbell, E. (2009). Editorial: The educated person. Curriculum Inquiry, 39(3), 371-379. https://doi.org/10.1111/j.1467-873X.2009.00448.X

Conley, S. N., Foley, R. W., Gorman, M. E., Denham, J., \& Coleman, K. (2017). Acquisition of t-shaped expertise: an exploratory study. Social Epistemology, 31(2), 165-183. https://doi.org/10.1080/02691728.2016.1249435

Drew, S. (2012). Open up the ceiling on the common core state standards: Preparing students for 21st-century literacy now. Journal of Adolescent \& Adult Literacy, 56(4), 321-330. https://doi.org/10.1002/JAAL.00145

Farkas, G. (2003). Cognitive skills and noncognitive traits and behaviors in stratification processes. Annual Review of Sociology, 29, 541-562. https://doi.org/10.1146/annurev.soc.29.010202.100023

Fawcett, J., \& Gunson, R. (2020). Shaping the future: A21 st century skills system for Wales (pp. 3-6, Rep.). Institute for Public Policy Research (IPPR).

Georgia Institute of Technology. (n.d.). Creating the next in education: Whole person education. https://provost.gatech.edu/educational-innovation/reports/lifetime-education/initiatives/whole-person-ed ucation

Hanushek, E., \& Woessmann, L. (2008). The role of cognitive skills in economic development. Journal of Economic Literature, 46(3), 607-668. https://doi.org/10.1257/jel.46.3.607

Heckman, J., \& Rubinstein, Y. (2001). The importance of non-cognitive skills: Lessons from the GED testing program. The American Economic Review, 91(2), 145-149. https://doi.org/10.1257/aer.91.2.145

Herman, R., Dinicola, S., Armentrout, C., \& Ross, S. (2019). (Rep.). RAND Corporation. https://doi.org/10.2307/resrep19895

Hernando-Malipot, M. (2018, January 25). Concerns over job readiness hound first batch of $k$ to 12 graduates. Manila Bulletin.

https://news.mb.com.ph/2018/01/25/concerns-over-job-readiness-hound-first-batch-of-k-to-12-graduate s/Higher Education

Honebein, P. C. (1996). Seven goals for the design of constructivist learning environments. In B. G. Wilson 
(Ed.), Constructivist learning environments: Case studies in instructional design (pp. 11-24). Englewood Cliffs, NJ: Educational Technology Publications.

Hozjan, D. (2009). Key competences for the development of lifelong learning in the European Union. European Journal of Vocational Training, 46(1), 196-207.

Lamon, M. (2020). Learning theory: Constructivist approach. https://education.stateuniversity.com/pages/2174/Learning-Theory-CONSTRUCTIVIST-APPROACH. $\underline{\mathrm{html}}$

Lefoe, G. (1998). Creating constructivist learning environments on the web: the challenge in higher education. Centre for Educational Development and Interactive Resources, University of Wollongong, Australia. https://www.ascilite.org/conferences/wollongong98/asc98-pdf/lefoe00162.pdf

Logsdon, L. (2013). Questioning the role of "21st-century skills" in arts education advocacy discourse. Music Educators Journal, 100(1), 51-56. https://doi.org/10.1177/0027432113499936

London, P. (2006). Towards a holistic paradigm of art education art education: Mind, body, spirit. Visual Arts Research, 32(1), 8-15.

Lovat, T., Clement, N., Dally, K., \& Toomey, R. (2010). Values education as holistic development for all sectors: Researching for effective pedagogy. Oxford Review of Education, 36(6), 713-729. https://doi.org/10.1080/03054985.2010.501141

McLeod, S. A. (2019, July 17). Constructivism as a theory for teaching and learning. Simply Psychology. https://www.simplypsychology.org/constructivism.html

Merrow, J. (2006). My college education: Looking at the whole elephant. Change, 38(3), 8-15. https://doi.org/10.3200/CHNG.38.3.8-15

Murnane, R., Willett, J., Duhaldeborde, Y., \& Tyler, J. (2000). How important are the cognitive skills of teenagers in predicting subsequent earnings? Journal of Policy Analysis and Management, 19(4), 547-568. https://doi.org/10.1002/1520-6688(200023)19:4<547::AID-PAM2>3.0.CO;2-\#

National Education Association. (n.d.). Preparing 21st century students for a global society: An educator's guide to the "four Cs". http://www.nea.org/assets/docs/A-Guide-to-Four-Cs.pdf

Neeley, K. A., \& Steffensen, B. (2018, June 24-27). The t-shaped engineer as an ideal in its origins, history, and significance for engineering education. Paper presented at the ASEE Annual Conference \& Exposition (American Society for Engineering Education), Salt Lake City, Utah.

Nehring, J., Charner-Laird, M., \& Szczesiul, S. (2017). What real high performance looks like. The Phi Delta Kappan, 98(7), 38-42. https://doi.org/10.1177/0031721717702630

Pascual, A. C. T. (2019, February 1). Is there a job waiting for senior high-school graduates? Business Mirror. https://businessmirror.com.ph/2019/02/01/is-there-a-job-waiting-for-senior-high-school-graduates/

Pitagan, F. B., Andres, V. P., Plaza, L. M. N., Rotor, C. C., \& Villanueva, C. F. (2016). Media and information literacy: Teaching guide for senior high school. Quezon City, Philippines: Commission on

Republic Act No. 10533 (2013, May 15). Official Gazette, Republic of the Philippines. https://www.officialgazette.gov.ph/2013/05/15/republic-act-no-10533/

Saavedra, A., \& Opfer, V. (2012). Learning 21st-century skills requires 21st-century teaching. The Phi Delta Kappan, 94(2), 8-13. https://doi.org/10.1177/003172171209400203

Santos, R. I. (2019, October 29-30). Developing intelligent, social, and moral potentials among junior college students: A Philippine technology-based 21CC model. Paper presented at the Opportunities and Challenges in Southeast Asia Conference, Soegijapranata Catholic University, Central Java, Indonesia.

Santos, R. I. (2020). Toward a $21^{\text {st }}$-century model in media and information literacy instruction in Philippine senior high schools. Manuscript submitted for publication.

Silva, E. (2009). Measuring skills for 21st-century learning. The Phi Delta Kappan, 90(9), 630-634. https://doi.org/10.1177/003172170909000905

Taherdoost, H. (2016). Sampling methods in research methodology; How to choose a sampling technique for research. International Journal of Academic Research in Management, 5 (2), 18-27. https://doi.org/10.2139/ssrn.3205035

Tan, J. P., Choo, S.S., Kang, T., \& Liem, G. A. D. (2017). Educating for twenty-first century competencies and 
Output-based approach in media and information literacy toward 21st century skills development future-ready learners: research perspectives from Singapore. Asia Pacific Journal of Education, 37(4), 425-436. https://doi.org/10.1080/02188791.2017.1405475

Tan, J. P., Koh, E., Chan, M., Costes-Onishi, P., \& Hung, D. (2017). Advancing 21st century competencies in Singapore. Center for Global Education. Asia Society.

https://asiasociety.org/sites/default/files/2017-10/advancing-21st-century-competencies-in-singapore.pd $\underline{\mathrm{f}}$

Vidyarthi, S., Winkle, C., Smith, J., Zhang, T., Kawamura, K., \& Hoch, C. (2012). Holistic, inclusive and practical: Teaching plan-making at the core. The Town Planning Review, 83(6), 625-645. https://doi.org/10.3828/tpr.2012.40

Wright, E., \& Lee, M. (2014). Developing skills for youth in the 21st century: The role of elite international baccalaureate diploma programme schools in China. International Review of Education, 60(2), 199-216. https://doi.org/10.1007/s11159-014-9404-6 
Santos, R.

30 Consortia Academia Publishing (A partner of Network of Professional Researchers and Educators) 